\title{
Celestial calendar-paintings and culture-based digital storytelling: cross-cultural, interdisciplinary, STEM/STEAM resources for authentic astronomy education engagement
}

\author{
Annette S. Lee ${ }^{1}$, William Wilson ${ }^{2}$, Jeff Tibbetts ${ }^{3}$, Cark Gawboy $^{4}$, Anne Meyer ${ }^{5}$, Wilfred \\ Buck $^{6}$, Jim Knutson-Kolodzne ${ }^{7}$, David Pantalony ${ }^{8}$ \\ ${ }^{1}$ Department of Physics and Astronomy, St. Cloud State University, 740 Fourth Ave. S., St. Cloud, \\ Minnesota, 56301, USA; Fond du Lac Tribal and Community College, $210214^{\text {th }}$ Street, Cloquet, \\ Minnesota, 55720, USA \\ ${ }^{2}$ Consultant, Ojibwe language and culture; visual artist, Minnesota, USA \\ ${ }^{3}$ Fond du Lac Tribal and Community College, 2102 14th Street, Cloquet, Minnesota, 55720, USA \\ ${ }^{4}$ (Emeritus) College of St. Scholastica, Department of Am. Ind. Studies, 1200 Kenwood, Duluth, \\ MN, 55811, USA \\ ${ }^{5}$ Consultant, visual artist, art educator Minnesota, USA \\ ${ }^{6}$ Manitoba First Nations Education Resource Centre, 2-1100 Waverly St., Winnipeg, Manitoba R3T \\ 3X9, Canada \\ ${ }^{7}$ Director of the SCSU American Indian Center, St. Cloud State University, 740 Fourth Ave. S., St. \\ Cloud, Minnesota, 56301, USA \\ ${ }^{8}$ Curator, Physical Sciences and Medicine, Conservateur, Sciences physiques et médecine Ingenium - \\ Canada's Museums of Science and Innovation, Musées des sciences et de l'innovation du Canada, \\ Ottawa, Ontario
}

\begin{abstract}
In $\mathrm{D}(\mathrm{L})$ akota star knowledge, the Sun is known as $W i$ and the Moon is Han-Wi. They have an important relationship, husband and wife. The pattern of their ever-changing relationship is mirrored in the motions of Sun and Moon as seen from our backyards, also called the lunar phases. The framework of the cultural teaching is storytelling and relationships. Cultural perspectives in astronomy such as this remind us of how indigenous ways of knowing are rooted in inclusion, engagement, and relevancy. Designed by A. Lee in 2007, the Native Skywatchers initiative seeks to remember and revitalize indigenous star and earth knowledge, promoting the native voice as the lead voice. The overarching goal of Native Skywatchers is to communicate the knowledge that indigenous people traditionally practiced a sustainable way of living and sustainable engineering through a living and participatory relationship with the above and below, sky and earth. In 2012 two indigenous star maps were created: the Ojibwe Giizhig Anung Masinaaigan-Ojibwe Sky Star Map (A. Lee, W. Wilson, C. Gawboy), and the $\mathrm{D}(\mathrm{L})$ akota star map, Makoce Wicanhpi Wowapi (A. Lee, J. Rock). In 2016, a collaboration with W. Buck of the Manitoba First Nations Resource Centre (MFNRC), produced a third star map: Ininew Achakos MasinikanCree Star Map Book. We aim to improve current inequities in education for
\end{abstract}


native young people especially through STEM engagement, to inspire increased cultural pride, and promote community wellness. Presented here will be recently created resources such as: astronomical calendar-paintings and short videos that exist at the intersection of art-science-culture. As we look for sustainable ways to widen participation in STEM, particularly in astronomy education, part of the conversation needs to consider the place for art and culture in STEM.

\section{Introduction}

\subsection{Overview and Need}

Despite enormous effort and millions of funding dollars to improve K-12 STEM education, inequities persist across the US. Nowhere is the inequity more pronounced than with Native American students. Native students are more likely to drop out of high school and more likely to be placed in special education than any other race nationally (Allen, 1997). There are over 20,000 native students in Minnesota, (2\% of the total students), yet only 249 native teachers are working in the K-12 schools (0.4\%) (MDE 2017). Educational inequity is evident in high school graduation rates. For years, Minnesota has been near the bottom of the list for on-time graduation rates of students of color. Fewer than $50 \%$ of native high school students graduate on time (Post, 2015), while 85\% of white students in Minnesota graduate on time. Minnesota has one of the nation's greatest educational disparities between majority students and students of color (Post, 2015).

In 2009 the Minnesota Department of Education released the official State Science Standards for K-12 education. One standard requires teachers to include how underrepresented cultural groups have contributed to science, "Men and women throughout the history of all cultures, including Minnesota American Indian tribes and communities, have been involved in engineering design and scientific inquiry." (MDE 2009) Benchmark 3.1.3.2.1 specifically states "Understand that everybody can use evidence to learn about the natural world, identify patterns in nature, and develop tools. For example: Ojibwe and Dakota knowledge and use of patterns in the stars to predict and plan." (MDE 2009)

In addition to state science standards that promote cultural relevancy, each school district in Minnesota that has ten or more American Indian students can apply for Federal and State funding through the MN Office of Indian Education. Currently the Office administers the American Indian Education Aid program, which serves 143 eligible school districts, charters, and Bureau of Indian Education tribal contract schools. The number of school districts that do apply for the grants has increased every year. Each school district's superintendent and American Indian Advisory Parent Committee decide how to use the funding. Some hire staff to operate an American Indian Education program, others assign a district employee to oversee the grants. There is a loose network of American Indian education coordinators, directors, advocates, or district staff that meet on their own. The MDE Indian Education department provides moral support, education materials resources and advice. Usually it is up to the American Indian parents in a school district to put pressure on the school district to meet the needs of their children. The Native Skywatchers research and programming initiative works closely with many of the American Indian educator liaisons throughout the state delivering educator training workshops and indigenous STEM resources. 


\section{Native Skywatchers Goals and Objectives}

\subsection{Resource Development and Delivery}

In 2007 A. Lee created the Native Skywatchers (NSW) research and programming initiative with the vision of revitalizing the Ojibwe and $\mathrm{D}(\mathrm{L})$ akota native star knowledge. The overarching goal of NSW is to communicate the knowledge that indigenous people traditionally practiced a sustainable way of living and sustainable engineering through a living and participatory relationship with the above and below, sky and earth. The aim of NSW is to improve current inequities in education for native young people, to inspire increased cultural pride, and promote community wellness. The hope is to rekindle or deepen a sense of awe and personal relationship to the cosmos for all people.

"I used to look up and see the Greek constellations, like the Big Dipper, or Leo the lion... but now I know that there are stars up there that are ours. It does something to me inside, to have that relationship with the stars. It's like finding a long-lost relative." - J. Tibbetts, 2010

Funding awarded through NASA - MN Space Grant (MNSG), St. Cloud State University (SCSU) and Fond du Lac Tribal and Community College (FDTLCC) from 2009-2015 allowed NSW to develop resources and deliver community based programming over a sixyear period. In 2012, for the premier Native Skywatchers (NSW) Educator \& Community Workshop, two native star maps were designed and delivered: 1.) Ojibwe Giizhig Anung Masinnagan (Fig. 1) (A. Lee, et al., 2012), and 2.) D(L)akota Makoce Wicanhpi Wowapi (Fig.2) (A. Lee, et. al, 2013).

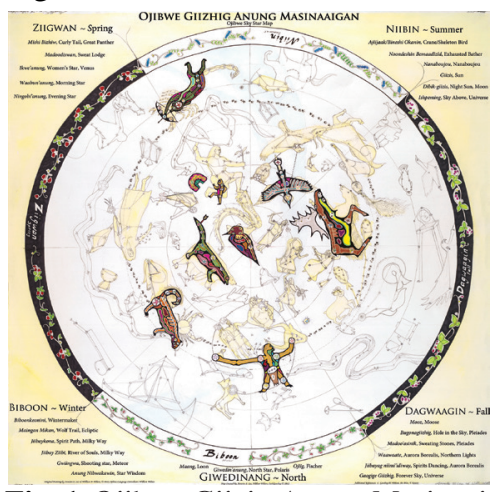

Fig. 1 Ojibwe Giizig Anung Masinaaigan, A. Lee et. al., 2012

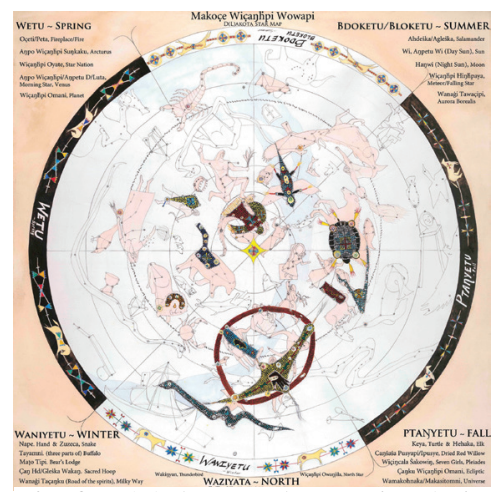

Fig. $2 D(L)$ akota Makoce Wicanhpi Wowapi,

A. Lee, et. al., 2012

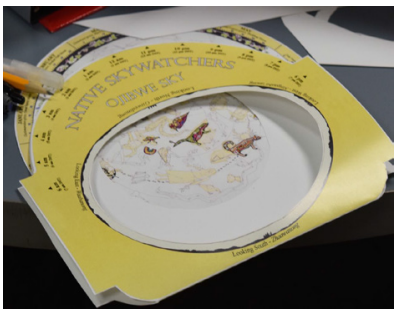

Fig. 3- NSW Ojibwe Planisphere
Using the native star maps as a foundational resource, many additional related resources were designed and delivered to educators and communities throughout the state, examples include: constellation guidebooks, make-it-yourself planispheres, lesson plans and worksheets compiled in a Native Skywatchers Curriculum Workbook, audio recording of native celestial vocabulary, power point presentations, etc. (Figs. 3-7). 


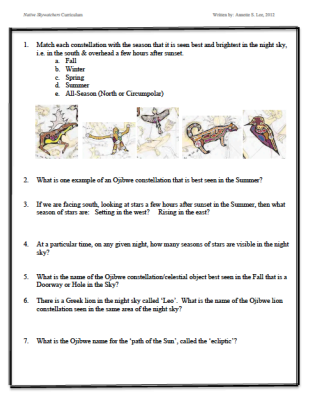

Figs. 4 \& 5 - Sample NSW Worksheets

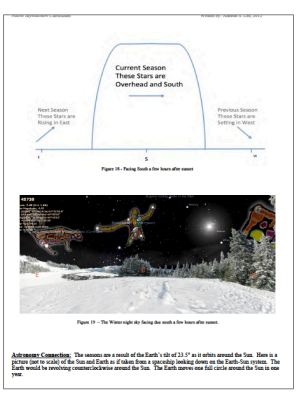

\subsection{Native Skywatchers (NSW) Expansion Efforts}

The NSW approach explores similarities between native ways of knowing the natural world and those of western science, toward the co-creation of a "dual-learning" system. Guided by the teaching "As it is above; it is below," the Earth-Sky relationship serves as the foundational framework of the NSW approach (Fig. 7). In this framework, the sky and stars are located above, the Earth (ground) is located below, and Anishinaabeg - the People - are fixed firmly and equally between the two, connecting them. The people are the stewards at the center of Earth and sky.

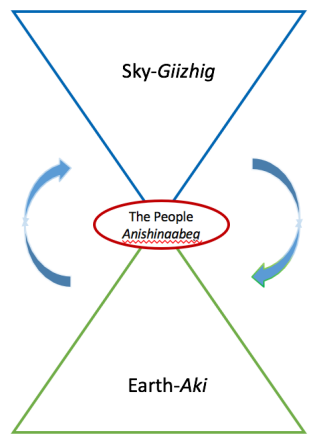

Fig 7 Earth Sky

Mirroring; Kapemni

Native astronomies helped to make sense of life and relationships and reaffirm the belief in the interrelationship and interdependence of all things in an animate and living universe. Like the Earth, plants, and animals, celestial bodies are traditionally viewed by Native cultures as living beings with a creative life force that relates to and affects human beings physically and spiritually. (Cajete, 2000)

Where the original aim of NSW was to focus on astronomical knowledge, it quickly became apparent that embedded in the sky was the reflection of the below-the earthand the human part in both. In 2014 the original premise of the astronomy focus was expanded to encompass earth-science content and cultural knowledge, for example: water, earth, air, and fire...and/or... hydrology, geology, atmospheric science, and energy resources.

Since 2014 NSW has received state funding through the Minnesota State Arts Board (MSAB) to design and deliver art-making interdisciplinary community based programming. Deliverables included: hands-on workshops and a touring exhibit. Across the state over 40 art-focused NSW workshops have been delivered primarily in native communities. Participants ranged in age from youth to elders. Venues included community centers, history/culture museums, schools, parks, libraries, art galleries, and medical clinics. In addition, a one-year traveling exhibit (2017-2018) showcases this work and widens the participatory circle. Over thirty, mostly native, artist-participants from professionals to beginners share their stories of a personal connection to earth and sky in this state-wide multi-media exhibit. The strength of this work is its interdisciplinary nature. Science, culture, and art, are woven together with diligent purposefulness.

- "The teacher (Annette) presented science as though it is connected to us in our everyday lives." 
- "The art we created seemed philosophical - as though the science of the skies had a connection to how we think and feel about the world. And our art reflects that feeling.

- "Thank you for sharing the science of our world with the native journey and taking me in a new exciting direction."

- Selected quotes, MSAB-Arts Learning participants 2015-2016

In 2015, NSW team-members A. Lee and W. Wilson were given tobacco by a representative, Wilfred Buck, from the Ininew (Cree) nation based in Winnipeg at the Manitoba First Nations Education Resource Center (MFNERC). This collaboration yielded a third native sky map, Ininew Achakos Masinkan, created in 2016 and based on 30 years of community based research by W. Buck (Fig.8).

Together, A. Lee and W. Buck were invited by Canada's Science and Technology Museum to co-curate (along with permanent curator D. Pantalony) an indigenous astronomy exhibit built on the grass-roots community-based research and programming that has occurred over the past three decades. This exhibit is called "One Sky - Many Astronomies" and is part of the complete renovation of the museum opening Nov. 2017.

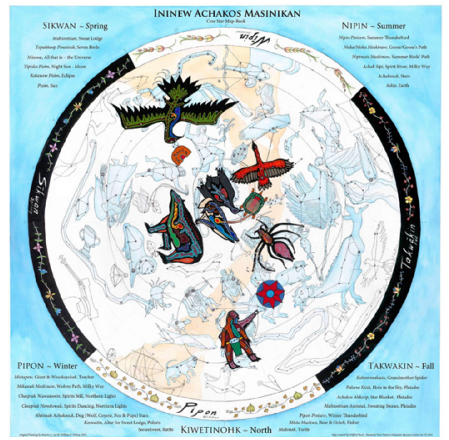

Fig 8 - Ininew Achakos Masinikan, A. Lee, W. Wilson, W. Buck, 2016
"Through thousands of years of observation and recognition of patterns in plants, animals, seasons and the sky, First Peoples built knowledge about the world around them...The sky maps and illustrations on this wall represent stories about stars and constellations that are deeply woven into the identity of Ininew, Ojibwe and $D(L)$ akota peoples."... Without reconnecting to spirit, Achak, we risk losing the knowledge that is inherent in Misewa, "All that is" and the idea of creation and learning without limits, and that is never ending.

- W. Buck 2017, One Sky-Many Astronomies exhibit

\section{Native Skywatchers Approach}

\subsection{Focus on Cultural Relevancy}

The NSW project draws strength from the growing body of evidence that culturally-relevant pedagogy increases student success. One recent study in Hawai'i, which gathered data from nearly 3000 students, 600 teachers and over 2000 parents, concluded:

First, culture-based education (CBE) positively impacts student socialemotional well-being (e.g., identity, self-efficacy, social relationships). Second, enhanced socio-emotional well-being, in turn, positively affects math and reading test scores. Third, CBE is positively related to math and reading test scores for all students, and particularly for those with low socio-emotional development, most notably when supported by overall CBE use within the school. (Kana'iaupuni, Ledward, and Jensen 2010) 
Culturally-relevant pedagogy is grounded in the idea that culture is always present. Norms, values, beliefs, and assumptions in Western scientific and indigenous culture are welcomed and honored in a dual-learning system. A dynamic is introduced and upheld that begins with the recognition that indigenous cultural knowledge is valuable, relevant, and meaningful. Educators and students learn to recognize, utilize, and value different approaches to teaching and learning.

One example of culturally relevant pedagogy is the NSW interdisciplinary workshop, "Carving your Animal Clan", led by Native Skywatchers team-member J. Tibbetts (Fig. 9-12). These workshops allowed participants to learn about the Ojibwe clan system, and to learn the geologic story of the 'rocks under our feet'. Many participants were surprised that 1 billion years ago North America attempted a mid-continental split and

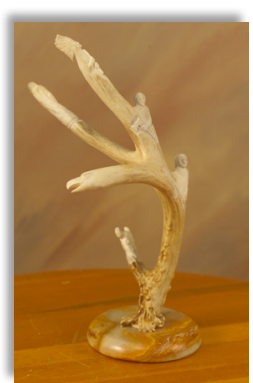

Fig. 9 Antler carving, J. Tibbetts

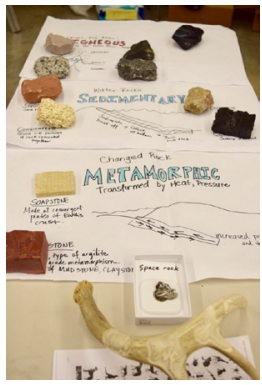

Fig. $10 \mathrm{NSW}$ workshop Minnesota would have become the new 'west coast' of the eastern half of North America. Important culturally relevant teachings were layered into the discussion such as, the use of basalt in the sweat lodge ceremony madoodiswan, and the Ojibwe Madoodiswan, Sweat Lodge constellation (Corona) in the night sky. The workshops are designed to give participants the opportunity to digest the ideas of the artwork, the culture and the science and then to 'make it their own'. Participants are given the materials to carve their own animal clan. Realistically not all native or mixed-race native participants are knowledgeable about their family clan. Much tradition has been lost. Participants are encouraged to talk to local elders and to focus in the short term on an animal that has meaning to them.

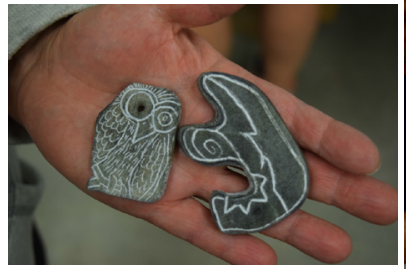

Fig 11-NSW Participant carvings, 2017

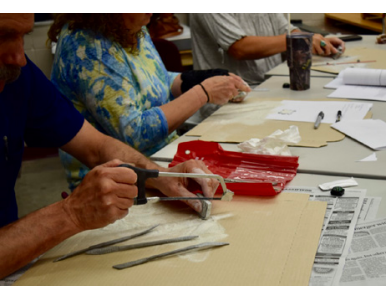

Fig 12- NSW Participants, 2017

\subsection{Focus on Storytelling}

Humans beings have relied on storytelling as a primary means of communication since our infancy as a species over 30,000 years ago. Native cultures have practiced oral tradition for tens-of-thousands of years. Medical research has shown that our brains are wired to learn and remember better by stories (Schwertly 2014). "Research shows our brains are not hardwired to understand logic or retain facts for very long. Our brains are wired to understand and retain stories." (Gottschall 2013) Even more interestingly, while the brain listens to a story, "the brain doesn't look like a spectator, it looks more like a participant in the action." (Gottschall 2013) The research and community programming of the Native Skywatchers initiative is focused on storytelling as an effective method of learning and teaching. For example, the Ojibwe Giizhig Anung Masinnaaigan, native star map is an astronomical map of the night sky, a teaching tool. Woven into this map are countless stories about each of the constellations, the planets, the seasons, and the language. There are layers of stories and volumes of knowledge. There are cultural stories and personal stories. In the northern hemisphere winter night sky, a viewer wearing an Ojibwe cultural lens can see 
Biboonkeonini-the Wintermaker. A viewer from the Western science perspective can see Orion. The Ojibwe stories in this case relate to how "Each season has certain spirits that make that season happen." (A. Lee et. al. 2014) and how the Wintermaker was defeated by the duck. (Gawboy 2014). Western science stories tell us of the star formation and planetary system accretion happening in the Orion Nebula. Both the Ojibwe perspective and the Western science perspective have a valuable and interesting story to tell. Here the intent is to weave both stories together in a tapestry that is dense with knowledge. Since 2016 NSW resource development includes short story-telling videos, such as Wintermaker and Ojiig, two Ojibwe constellations in the night sky, stories told by C. Gawboy, videos produced by A. Lee (Figs. $13 \& 14)$.

\subsection{Focus Place Based Relevancy}

The NSW project emphasizes culturally-relevant place-based learning and teaching. Placebased education engages students and communities, breaks down Native students' "boredom" (Platero, 1986; Deyhle, 1989), and demonstrates that the application of science and its results have tangible local significance. "In the natural sciences, place-based pedagogy is advocated as a way to improve engagement and retention of students, particularly members of indigenous or historically inhabited communities" (Semken 2008). Because the NSW project focuses on culturally-relevant pedagogy and place-based research, the project roots itself in history and location while making global connections.

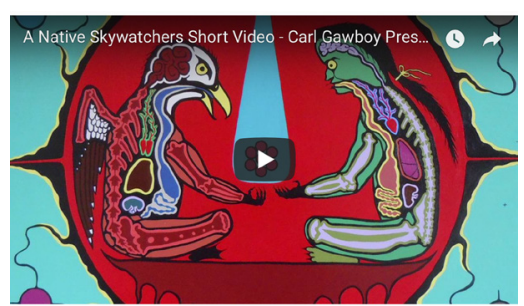

Fig 13- Wintermaker Video, C. Gawyboy \& A. Lee, 2016

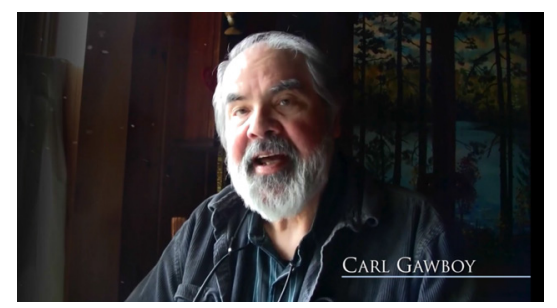

Fig 14- Ojiig Video, C. Gawboy \& A. Lee, 2016

One NSW interdisciplinary workshop called, "Be Humble for you are made of Earth", led by A. Meyer tells the story of the clay (Figs. 15-18). Here the science story is presented to participants. This includes the last glacial melt approximately 15,000 years ago and the formation of the 10,000 lakes that Minnesota is known for, as well as till, moraines, and Glacial Lake Agassiz. Alongside this idea is the exploration of pottery shards from the indigenous people living in the Minnesota area 3000 years ago, and some traditional Ojibwe and $\mathrm{D}(\mathrm{L})$ akota views of clay. Such as the use of catlinite/claystone (a mass of limestone found in a clay deposit, commonly called 'pipestone') to make the sacred pipe (https://en.wikipedia.org/wiki/Catlinite). In the D(L)akota star map, the constellation

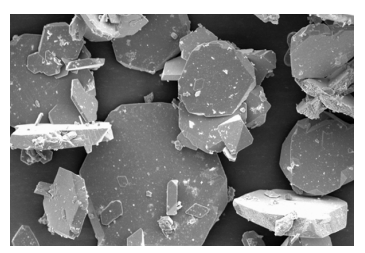

Fig 15-Flat platelets of clay

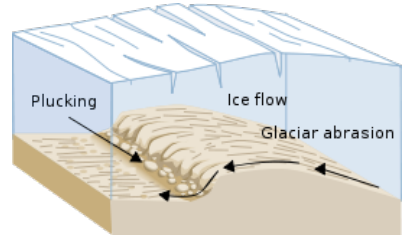

Fig 16-Glacial plucking, L. Benitez, 2004

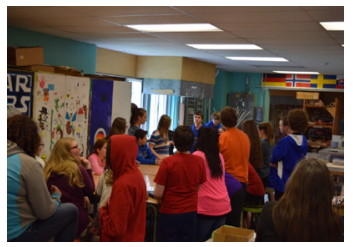

Fig. 17-NSW

Interdisciplinary workshop 
Cansasa Pusyapi, Red Willow, relates to the Pipe Ceremony. It is said, that "the bowl of the pipe comes from the blood of the people". (O'Rourke 1993)

\subsection{Focus on the Visual Language}

Learning to think and communicate visually has become increasingly important in both mainstream society and in

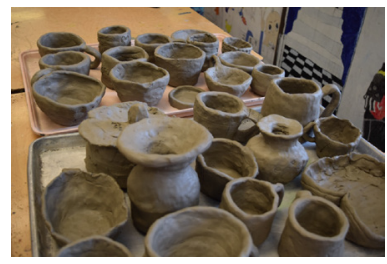

Fig. 18-Participant clay works pre-firing academia (CSTS 2006). The scientific method itself was inspired by evidence based entirely on the visual, for example: Brahe's almanacs (Brahe 1588, 1572), and Galileo's sketches (Galileo 1610, 1632). It has been shown that scientists have an "almost obsessive preoccupation with visual representations..." and that "...visual representations are central to the work creating science and to communicating science to others." (McGinn, Roth, 1999) Another group found that: "...children with developed visual perception, visual thought and representational skills are actually better with numbers and physical concepts" (Stavridou \& Kakana 2008). A National Academy of Sciences report determined that spatial thinking is 1.) woven into the fabric of our daily lives; 2 .) integral to successful problem solving, and 3.) is "under-recognized, undervalued, underappreciated, and therefore, under-instructed." (CSTS 2006).

In 2016 the Native Skywatchers initiative increased and expanded efforts in the development of educational indigenous STEM resources. Amplified efforts were directed towards the Ojibwe and $\mathrm{D}(\mathrm{L})$ akota cultural perspectives of the Moon and the Sun. This request came from many K-12 teachers and/or American Indian liaisons who were already implementing the native star maps in their classrooms. In comparison to the constellation material which appears in two substrands (in the third and eight grade curriculum standards), the Sun and the Moon content focus appears in eight substrands.

Native Skywatchers (NSW) celestial calendars are a 'first step' in rethinking the established teaching and learning approach to Sun and Moon. The first Moon calendar, "Our Moon" was produced in 2016 uses a rectangular grid layout, and relies heavily on color and texture to convey the phases of the Moon for each day of the year (Fig. 19). New Moons are coal black with green shadows. Full Moons are a heavily textured off-white bathed in a crimson red wash. In 2016 a second Moon calendar was created (Fig. 20). Here the layout of a circle was chosen to more appropriately match the cyclical motion of the Moon. Imagine standing at the center of the larger circle, then looking outward radially. The phase of the

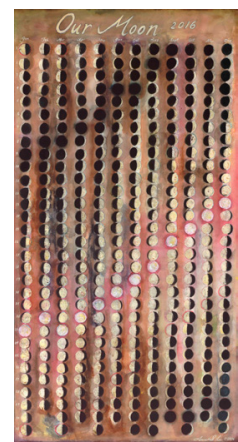

Fig. 19-Our Moon, A. Lee, 2016

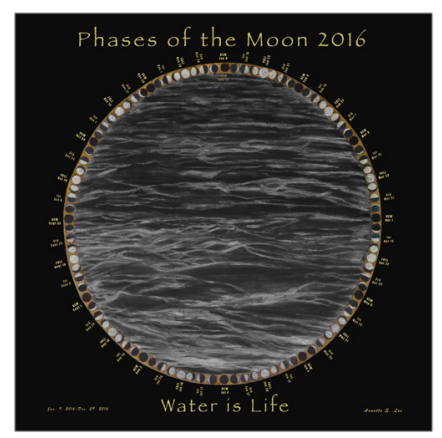

Fig. 20-Water is Life Moon, A. Lee, 2016

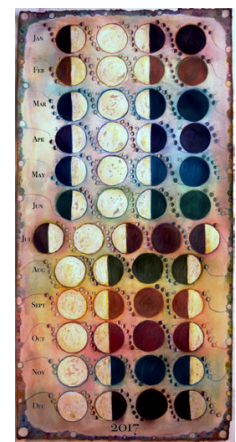

Fig. 21-Our Moon, A. Lee 2017 
Moon can be seen every three days from Jan. 1, 2016 to Dec. 31, 2016. The phases move around in a clockwise direction. This celestial lunar calendar is a visual springboard for the interwoven teachings between the Moon, water, and life. In 2017 a third Moon calendar was produced with a focus on the four main Moon phases- new, first, full, third (Fig. 21). It is important that the work is relevant, and most viewers of the sky have a basic knowledge of at least one or two of the four

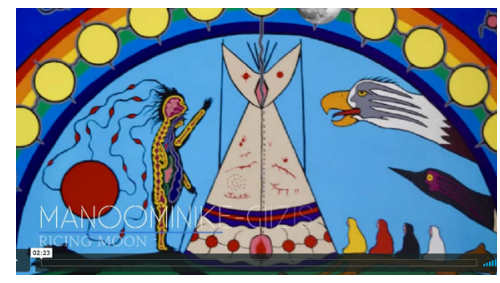

Fig. 22 Ojibwe Moons, A. Lee \& W.

Wilson, 2017 main lunar phases. This common ground is key to building the next layers of understanding and discussion. Following the lunar calendar paintings, lesson plans, worksheets, and a short video on the Ojibwe Moons were created (Fig. 22).

In 2016 and 2017 Sun calendars were created as an interdisciplinary learning tool (Figs. 23 \& 24). Much like the Lunar Phase celestial calendars, the Sun's path for a viewer looking towards the south meridian is shown for the year. Here the local maximum and minimum hours of daylight can easily be seen to correspond the longer/highest and shortest/lowest paths of the Sun. A viewer in central Minnesota can expect about 15. 5 hours of daylight around the Summer Solstice June 21, and about $8.5 \mathrm{hrs}$. of daylight around the Winter Solstice $\sim$ Dec. 21 each year.

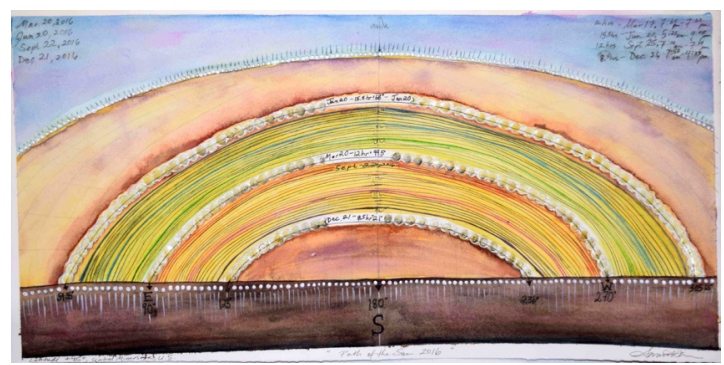

Fig 23-Path of the Sun, A. Lee, 2016

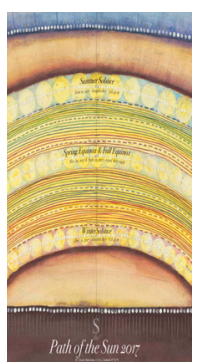

Fig 24-Path of the Sun, A. Lee, 2017

\section{Conclusions}

\subsection{Widening Participation in STEM}

Based on available data, Native Americans are facing a crisis in STEM education. Traditionally, Native American people saw themselves as stewards of the natural world, and there is clearly a disconnect in education systems that have failed to tap into what should be an area of interest. Minnesota Compass, a social indicators project, gleans the following from the National Assessment of Educational Progress: In 2015, Native American 4th graders reported the least interest in science of all student populations in Minnesota. In 2016, less than $40 \%$ of Native American 5th graders achieved Minnesota science standards. In 2017, Native American 8th graders ranked lowest (less than 30\%) in meeting Minnesota math standards. 


\subsection{Relevancy, Identity, and Cultural pride}

The NSW project fosters a dual-learning environment in which the stories told by science and native cultures (particularly Ojibwe and $\mathrm{D}(\mathrm{L})$ akota) are woven together into a tapestry - an image that ultimately reveals new and deeper meaning than could not be found in any of the threads alone. In this way, Native American students are encouraged to approach, pursue, and contribute to STEM without compromising their cultural identity. The work of the Native Skywatchers research and programming initiative aims to undermine this crisis. Since 2007 interdisciplinary resources that stand at the nexus of science, culture, and art have been designed and delivered by a team of native scientists, educators, cultural experts, and artists. The intent of this work is to promote the native voice as the lead voice in defining indigenous STEM. And at the same time the inclusion of culture should not diminish the science content, but rather open the door for wider participate and a fuller spectrum of teaching and learning engagement.

\section{References}

Allen, N., 1997, Indigenous models for science-and-culture curriculum development, Meeting of the National Association for Research in Science Teaching, Oak Brook, IL.

Brahe, T., 1588, Astronomiae Instauratae Progymnasmata (Introduction to the New Astronomy), orical archives

Brahe, T., 1602, De Mundi Aetherei Recentioribus Phaenomenis Liber Secundus (Second Book About Recent Phenomena in the Celestial World), historical archives

Cajete, G., Native Science: Natural Laws of Interdependence. Santa Fe: Clear Light Publishers, New Mexico, 2000.

Catlinite, https://en.wikipedia.org/wiki/Catlinite

Center for Digital Storytelling. 2005. Center for Digital Storytelling Web site. Retrieved Jan. 2017, from http://www.storycenter.org/history.html

Christopher, S., Watts, V., Building and Maintaining Trust in a Community-Based Participatory Research Partnership, 2008, American Journal of Public Health, 98(8), 1398-1406.

Committee on Support for Thinking Spatially (CSTS), 2006, Learning to think Spatially: GIS as a support system in the K-12 curriculum, Washington, DC: National Academies Press.

Dalbotten, D., Ito, E., Myrbo, A., Pellerin, H., Greensky, L., Howes, T., Wold, A., Breckenridge, R., Drake, C., Bucar, L., Kowalczak, C., Lindner, C., Olson, C., Ray, T., Rhoades, R., Woods, P., Yellowman, T., NSF-OEDG Manoomin Science Camp Project: A Model for Engaging American Indian Students in Science, Technology, Engineering, and Mathematics, Journal of Geoscience Education, 2014, 62(2), 227-243.

Deyhle, D., 1989, Pushouts and Pullouts: Navajo and Ute School Leavers. Journal of Navajo Education, 6 (2), 36-51.

Drijvers, P., Doorman, M., Boon, P., Reed, H., Gravemeijer, K., 2010, The teacher and the tool; instrumental orchestrations in the technology-rich mathematics classroom. Educational Studies in Mathematics, 75(2).

Galileo, G., 1632, Dialogue Concerning the Two Chief World Systems (Dialogo sopra i due massimi sistemi del mondo), historical archives

Galileo, G., 1610, Starry Messenger (Sidereal Messenger), historical archives 
Gawboy, C., Morton, R., 2014, Talking Sky, Duluth, MN: Rockflower Press

Gottschall, J., 2012, The Storytelling Animal: How Stories Make Us Human, Houghton Mifflin Harcourt Publishing

Kana'iaupuni, S., Ledward, B., Jensen, U., 2010. Culture-Based Education and Its Relationship to Student Outcomes, Honolulu: Kamehameha Schools, Research \& Evaluation, http://www.ksbe.edu/_assets/spi/pdfs/CBE_relationship_to_student_outcomes.pdf

Lee, A., 2016, Ojibwe Giizhiig Anung Masinaaigan and D(L)akota Makoce Wicanhpi Wowapi: Revitalization of Native American Star Knowledge, A Community Effort, Journal of Astronomy in Culture, 1(1), http://escholarship.org/uc/item/58m4f9pq.

Lee, A., Wilson, W., Tibbetts, J., Gawboy, C., 2014, Ojibwe Sky Star Map Constellation Guidebook-An Introduction to Ojibwe Star Knowledge, Cloquet, Minnesota: Avenue F Productions.

Lee, A., Rock, J., O'Rourke, C., 2014, D(L)akota Star Map Constellation Guide-An Introduction to $D(L)$ akota Star Knowledge, Cloquet, Minnesota: Avenue F Productions.

Lee, A., Rock, J., 2013, Native Skywatchers and the Makoce Wicanhpi Wowapi-D(L)akota Star Map - Building Community Around Native Star Knowledge, Astronomical Society of the Pacific Conference Series, 483, 133-147.

Lee, A., 2012, Native Skywatchers and the Ojibwe Giizhig Anung Masinaaigan: Ojibwe Sky Star Map, Astronomical Society of the Pacific Conference Series, 473, 29-41.

Manitoba First Nations Education Resource Center (MFNERC) website, https://mfnerc.org

McGinn M., Roth W., 1999, Preparing Students for Competent Scientific Practice: Implications of Recent Research in Science and Technology Studies, American Educational Research Association, 28(3).

McGrath, M., Brown, J., 2005, Visual Learning for Science and Engineering, IEEE Computer Graphics and Applications, 25(5), Sept.-Oct., p. 56-63.

Minnesota Compass. (2017). "Percent of $4^{\text {th }}$ Graders with High Interest in Science by Racial and Ethnic Group, Minnesota, 2015." STEM in Minnesota: Disparities. $<$ http://www.mncompass.org/education/stem/disparities/race-ethnicity>. (August 2017).

Minnesota Compass. (2017). " $5^{\text {th }}$ Grade Students Achieving Science Standards by Racial and Ethnic Group, Minnesota, 2016." STEM in Minnesota: Disparities. $<$ http://www.mncompass.org/education/stem/disparities/race-ethnicity >. (August 2017).

Minnesota Compass. (2017). " $8^{\text {th }}$ Grade Students Achieving Math Standards by Racial and Ethnic Group, Minnesota, 2017." STEM in Minnesota: Disparaties. $<$ http://www .mncompass.org/education/stem/disparities/race-ethnicity >. (August 2017).

Minnesota Compass. (2017). "Percent of $8^{\text {th }}$ Graders Doing Science Activities not for School by Racial and Ethnic Group, Minnesota, 2015." STEM in Minnesota: Disparaties. <http://www.mncompass.org/education/stem/disparities/race-ethnicity>. (August 2017).

Minnesota Department of Education. 2009, “Minnesota Academic Standards - Science K12",http://education.state.mn.us/MDE/EdExc/StanCurri/K-

12AcademicStandards/index.htm

Minnesota Department of Education, 2017 Report of Teacher Supply and Demand in Minnesota's Public Schools, Fiscal Year 2017 Report to the Legislature as required by Minnesota Statutes, Section 127A.05, Subdivision 6, http://www.leg.state.mn.us/lrl/lrl.asp 
Minnesota Office of Higher Education. "Graduation Rates by Race at Minnesota State Colleges, 2015." Research, Data \& Reports. Graduation Rates. https://www.ohe.state.mn.us/mPg.cfm?pageID=754. (August 2017).

Minnesota Office of Higher Education. "Graduation Rate Trends at Minnesota Institutions, 2004 - 2015." Minnesota Office of Higher Education https://www .ohe.state.mn.us/dPg.cfm?pageID=2086. (August 2017).

Monhardt, R. M., 2003. The image of the scientist through the eyes of Navajo children. Journal of American Indian Education, 42(3).

National Center for Science and Engineering Statistics, 2015, Women, Minorities, and Person with Disabilities in Science and Engineering: 2015, Spec. Rep. NSF 15-311, National Science Foundation, Arlington, Virginia.

National Council of Teachers of Mathematics (NCTM) 2008. The role of technology in the teaching and learning of mathematics, http://www.nctm.org/about/content.aspx?id\%BC14233

Native Skywatchers website, http://www.nativeskywatchers.com, 2012.

Platero Paperwork, Inc. (1986). Executive summary: Navajo area student dropout study. Window Rock, AZ: Navajo Division of Education, The Navajo Nation

O’Rourke, C., 1993, personal communication, Showlow, Arizona, July.

Post, T., 2015, "Minnesota Near Bottom in On-time Graduation for Students of Color", Minnesota Public Radio News, Feb. 19.

President's Council of Advisors on Science and Technology, 2012, Engage to Excel: Producing One Million Additional College Graduates with Degrees in Science, Technology, Engineering, and Mathematics, http:www.whitehouse.gov/sites/default/files/microsites/ostp/pcast-engage-to-excelfinal_feb.pdf

Robin, B., Digital Storytelling: A Powerful Technology Tool for the $21^{\text {st }}$ Classroom, Theory Into Practice, 47, 220-228, 2008

Rock, D. 2009, Your Brain at Work: Strategies for Overcoming Distraction, Regaining Focus, and Working Smarter All Day Long, Harper Collins, New York.

Schwertly, S., The Neuroscience of Storytelling, website, Oct. 2014, https://www.ethos3.com/2014/10/the-neuroscience-of-storytelling/

Semken, S., Freeman, C.B., 2008. Sense of place in the practice and assessment of placebased science teaching, Science Education, 92(6).

Stavridou, F. \& Kakana, D., 2008, Graphic abilities in relation to mathematical and scientific ability in adolescents, Educational Research, 50(1), March.

Tibbetts, J., 2010, personal communication, Cloquet, Minnesota, June. 